\title{
Comparative Study on Categories and Services of Fresh E- Commerce Platforms
}

\author{
Xi Sun ${ }^{1}$ \\ 1. Beijing University of Agriculture, Beijing, 102206, China
}

\begin{abstract}
Fresh e-commerce has attracted the attention of the capital market for its hundreds billion market scale, high repurchase rate, big market demand and large profits. More and more young and middle-aged people choose fresh e-commerce as the channel of fresh purchase to achieve faster speed, higher quality and more commodity categories. The price is no longer the only factor for consumers, especially for young and middle-aged consumers. This paper makes a comparative analysis of five fresh e-commerce platforms in terms of delivery time, third-party occupancy, and minimum consumption of "free distribution fee", members, communities, payment preferences, and e-commerce platform interface. In this paper, one hundred consumers are selected to evaluate the scores in respective modules, and the operation models of fresh e-commerce platform with different characteristics are comprehensively displayed. The paper points out that providing more quality and differentiated services has become an important competitive key point in the market.
\end{abstract}

\section{Introduction}

Fresh e-commerce refers to the e-commerce network platform that uses e-commerce network platform as the terminal retail channel to sell vegetables, meat, milk, eggs, aquatic products and other fresh products to consumers, and most of them are mobile network platforms. According to the panorama report of fresh retail industry in 2020 by Ping An Securities, the market share of traditional channels has continued to decline, from $62.3 \%$ in 2014 to $56.3 \%$ in 2019 in China's fresh retail industry. The market is gradually replaced by modern purchasing channels such as supermarkets and online shopping. With the outbreak of novel coronavirus pneumonia (COVID-19) in early 2020, the penetration of online business was gradually expanding. Due to the fixed delivery time, fast delivery time and contactless distribution, fresh electric business was favoured by more consumers after the Spring Festival of 2020. The fresh e-commerce market has also attracted the attention of the capital market due to the 100 billion market scale, high frequency, high repurchase rate, high market demand and large profits. This makes Alibaba, Tencent \& Jingdong, Suning, Meituan and other retail giants in the market layout. Therefore, in recent years, there have been Alibaba's box horse, Tencent \& Jingdong's Jingdong Home, Yonghui's Life and Missfresh, Suning's Carrefour and Suning's shop, Meituan's Meituan Shopping, etc.

This paper makes a comparative analysis of five fresh e-commerce platforms in terms of delivery time, thirdparty occupancy, minimum consumption of "free distribution fee", members, communities, payment preferences, and e-commerce platform interface to comprehensively display all levels of fresh e-commerce.

\section{Categories analysis of fresh e- commerce}

The following fresh electricity commodity analysis is based on the data statistics on February 12, 2021.

Taking $\mathrm{A}$ as an example, it is mainly divided into 15 varieties, including fresh vegetables, seasonal fruits, meat, poultry and eggs, seafood, instant cooked food, leisure food, dairy baking, wine and beverage, grain and oil seasoning, and daily necessities. At the same time, there are also related special activities to add, such as New Year gift box, New Year's Eve dinner, home hot pot, Esupermarket special sale, and member zone. In the category of fresh vegetables, there are nine categories. In the category of seasonal fruits, there are ten categories. In the category of meat, poultry and egg products, there are thirteen categories. In the category of seafood, there are ten categories of fresh vegetables. There are 10 categories of aquatic products, including chilled fish and frozen shrimps.

Taking B as an example, is divided into thirteen categories, such as fruits and vegetables, meat, poultry and eggs, seafood and aquatic products, quick frozen products, dairy baking, cereals and oils rest food, drinks, and beauty cares, etc. Different from other fresh e-commerce, in addition to the general categories, there are also life services, such as housekeeping, nanny and pet services. Among the fruits and vegetables, there are apple, pear, banana, leafy vegetables and other conventional varieties. At the same time, there are fruit cut salads, daily fresh vegetables and so on. In addition, there are flower shops 
to provide fresh flowers for sale. In the meat, poultry and egg products, there are thirteen categories, including all kinds of meat sales, daily fresh, proper season, Chinese New Year and Valentine's Day. In the seafood and aquatic products, there are three categories. There are fourteen categories of domestic seafood, fresh aquatic products and chilled aquatic products, and there are segments of sashimi, dry products and semi-finished products, which are convenient for consumers to choose.

Taking $\mathrm{C}$ as an example, divided into fourteen categories, such as vegetables and fruits, meat, eggs, aquatic products, dairy baking, etc. $\mathrm{C}$ has also recently updated its categories, adding life services, including washing care and housekeeping. In the category of vegetables and fruits, there are fresh vegetables and fresh fruits and vegetables. There are no more specific categories of vegetables and fruits. You need to search for them, and you cannot browse them directly according to the categories. In the category of meat, egg and aquatic products, according to aquatic products, meat products and egg products, the situation is the same as that of vegetables and fruits. From this situation, we can see that the classification of $\mathrm{C}$ is relatively rough and the degree of subdivision is not enough.

Taking D as an example, it is mainly divided into guess your favourite, special price, this week's new, global fashion, happy new year, imported goods, pets, silver hair life, mother and child's home and other special areas, as well as fresh fruits and vegetables, seasonal fresh vegetables, aquatic products and seafood and other conventional categories. There are nine kinds of seasonal vegetables, such as leafy vegetables, tomatoes, melons and fruits, and nine kinds of fresh fruits, including seasonal specials and gift boxes. In the classification of aquatic products and seafood, there are seven classifications.

Taking $\mathrm{E}$ as an example, it is mainly divided into sixteen categories, such as vegetable and bean products, meat, poultry and eggs, seafood and aquatic products, fruits, etc. among them, the thematic category includes five categories, namely, new year's goods street, happyeating fruit, nutritious breakfast, famous place in internet and container volume peddler. In the vegetable and bean products category, there are eleven categories. In the meat category, poultry and egg category, there are nine categories. In the seafood and aquatic products category, there are eleven categories. In the fruit category, there are 12 categories, except for recommendation, member zone, and new products in each major category and gift box / wholesale area.

From the comparative analysis of the above situation, we can see that the classification of $\mathrm{C}$ is relatively rough, and without further segmentation, more is to search according to the required products to obtain specific information, but not to browse according to the sub categories. In this way, when purchasing goods, the purpose is stronger, but the possibility of related purchase will reduce when browsing similar products, which is not conducive to the comparison it is related to the purchase of products, and reduces the amount of one-time purchase of products. Moreover, A, D and E are separated fruits and vegetables to facilitate consumers to browse. In a large number of categories, E and D are relatively more divided, but there are more special categories. Among the varieties with large household consumption, $\mathrm{B}$ and $\mathrm{A}$ are more reasonable and detailed. Both $\mathrm{B}$ and $\mathrm{C}$ have the classification of service commodities, but the service commodities of $\mathrm{C}$ are the third-party institutions' entry platform, and the service commodities of B are the selfservice of $B$.

Based on the evaluation of 100 consumers on the above five kinds of fresh electricity products, it can be seen that on the one hand, in terms of category management and category richness, the score of fresh electricity products is higher. On the other hand, the overall score of fresh electricity products is higher than "Online + Offline". Therefore, in terms of category richness and category management, consumers prefer fresh e-commerce, as shown in Figure 1.

\section{Scorces of categroies of 5 fresh e-commerce}
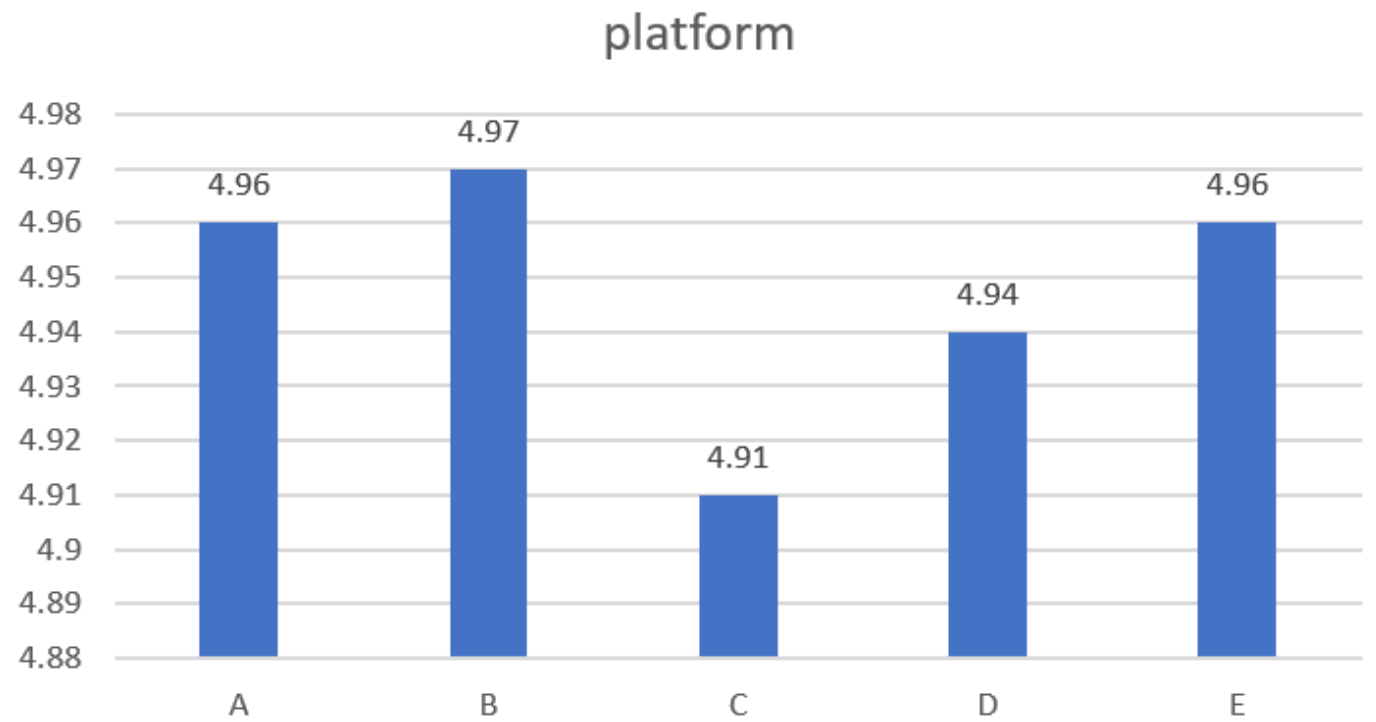

Figure 1. Evaluation of category management of fresh e-commerce 


\section{Services analysis of fresh e- commerce}

\subsection{Comparative analysis of delivery time}

In terms of delivery efficiency, Sample a focuses on the delivery of "Half an Hour at the Fastest", and the default time is within one hour from the time of placing the order. It can also make an appointment for delivery. The appointment time takes half an hour as a cycle, and the latest delivery time is 22:30. B takes half an hour after the scheduled time as the delivery start time, and takes half an hour as a timing cycle, and the latest delivery time is 22:00. E's main delivery time is the fastest 30 minutes, and the default time is half an hour when the time starts after 20 minutes. If you make an appointment for delivery, you can choose every half an hour after the default time as a timing period and the latest delivery time is $22: 30$. C's earliest delivery time is an hour, and 30 minutes as a timing period and you can make an appointment for any time after one and a half hours, the latest delivery time is 18 o'clock. D's main delivery time is within one hour, you can book every half hour after one hour as a time cycle and the latest delivery time is 18 o'clock.

From the above five fresh e-commerce delivery time point of view, the forward warehouse A, B, e delivery is more flexible, and the delivery can reach 10 p.m. or later, while the two supermarket e-commerce delivery deadline is relatively early, so the flexibility is not enough. In terms of the main delivery time slogan, the slogan of a highlights the advantage of arriving at home in time. From the actual comparison, the delivery time of a starts from placing an order, while B, D and other two start from about half an hour in actual delivery, most of which take half an hour as a timely cycle, so the actual delivery arrival time gap is not big. So from the convenience of delivery time, A, B and $\mathrm{E}$ are better than $\mathrm{C}$ and $\mathrm{D}$. Different from other fresh e-commerce platforms, a has a special zone for the next day, while other e-commerce's self-operated products do not have this distribution situation.

After 100 consumers scored the above five fresh ecommerce delivery time, it can be seen that on the one hand, fresh e-commerce gave a higher score in terms of delivery time. On the other hand, the overall score of fresh e-commerce was higher than "Online + Offline". In terms of delivery time and quality, consumers are more recognized by fresh e-commerce, as shown in Figure 2.

\section{Scores of delivery time of 5 fresh e-commerce platform}

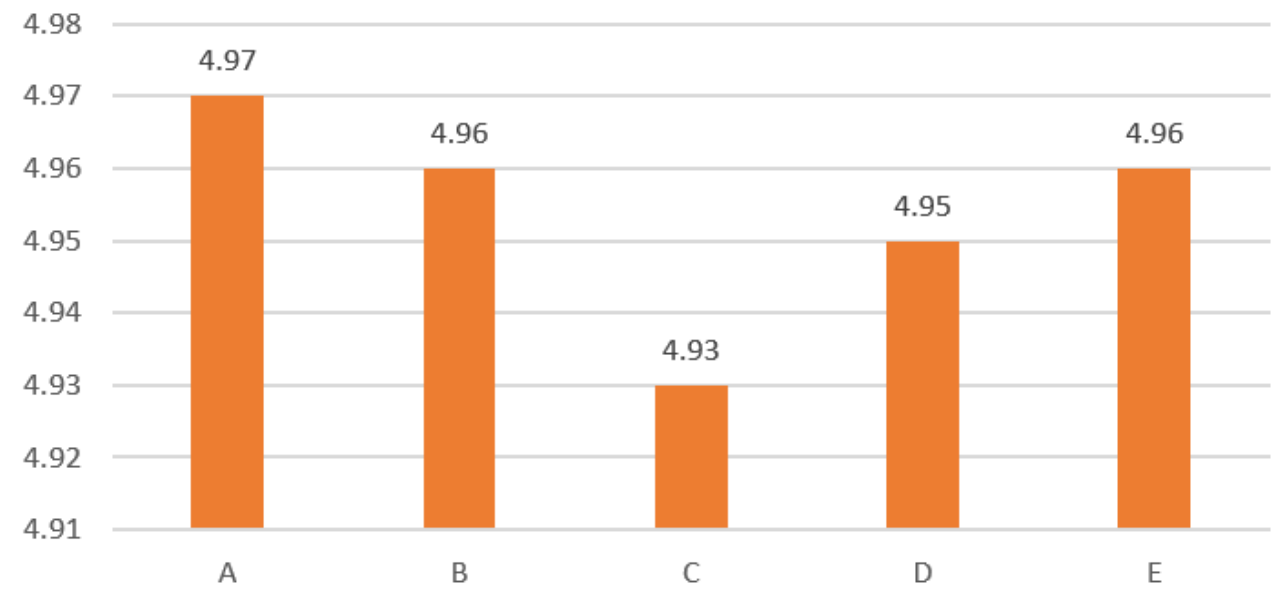

Figure 2. Evaluation of delivery time management of fresh e-commerce

\subsection{Comparative analysis of third party businesses entry}

Some e-commerce companies have third-party businesses. If a third-party merchant enters, the specific free mail policy or distribution policy will be implemented according to the specific agreed rules of the third-party merchant when purchasing the third-party merchant's products. $\mathrm{C}$ has a brand direct supply zone, while other fresh food e-commerce platforms do not.

\subsection{Comparative analysis of minimum consumption of "free distribution fee"}

The amount of free distribution fee of A is 39 Yuan, and the distribution fee that does not reach the amount is 6
Yuan. Since its launch, B has been using "0 Yuan as the starting point". Since August 2019, it has announced that the first order is free of charge and the second order is 5 Yuan as the starting point. However, in the period of tight transportation capacity, it will adopt the policy of charging different price distribution fees only. For example, there was a distribution fee of 16 Yuan per order between $10 \mathrm{pm}$ and $11 \mathrm{pm}, 10$ Yuan per order during the Spring Festival in 2019, and 6 Yuan per order during the Spring Festival in 2020. C is 79 Yuan or more, free of distribution fee, and 6 Yuan for those less than the amount. There is often a free distribution coupon to get. The amount of free distribution fee of D is 38 Yuan, and that of less than the amount is 6 Yuan. E can enjoy free distribution fee for the first order every day, free distribution fee for the first order is 38 Yuan, and the distribution fee for less than the amount is 5 Yuan. 
From the above comparative analysis, the amount of free distribution fee of $\mathrm{E}$ and $\mathrm{D}$ is 38 Yuan, but the first order of $\mathrm{E}$ is free of distribution fee, and even if the delivery amount is not full, the distribution fee is only 5 Yuan, and the amount of distribution fee is the lowest. Secondly, the order of consumption quota of free distribution fee from low to high is A and C. During the survey period, B charged 6 Yuan for distribution. ased on the evaluation of 100 consumers on the above five fresh e-commerce "free distribution fee", it can be seen that due to the amount of distribution fee and the minimum consumption amount of free distribution fee, $\mathrm{B}$ has the lowest score, while A, D and E have higher scores, as shown in Figure 3.

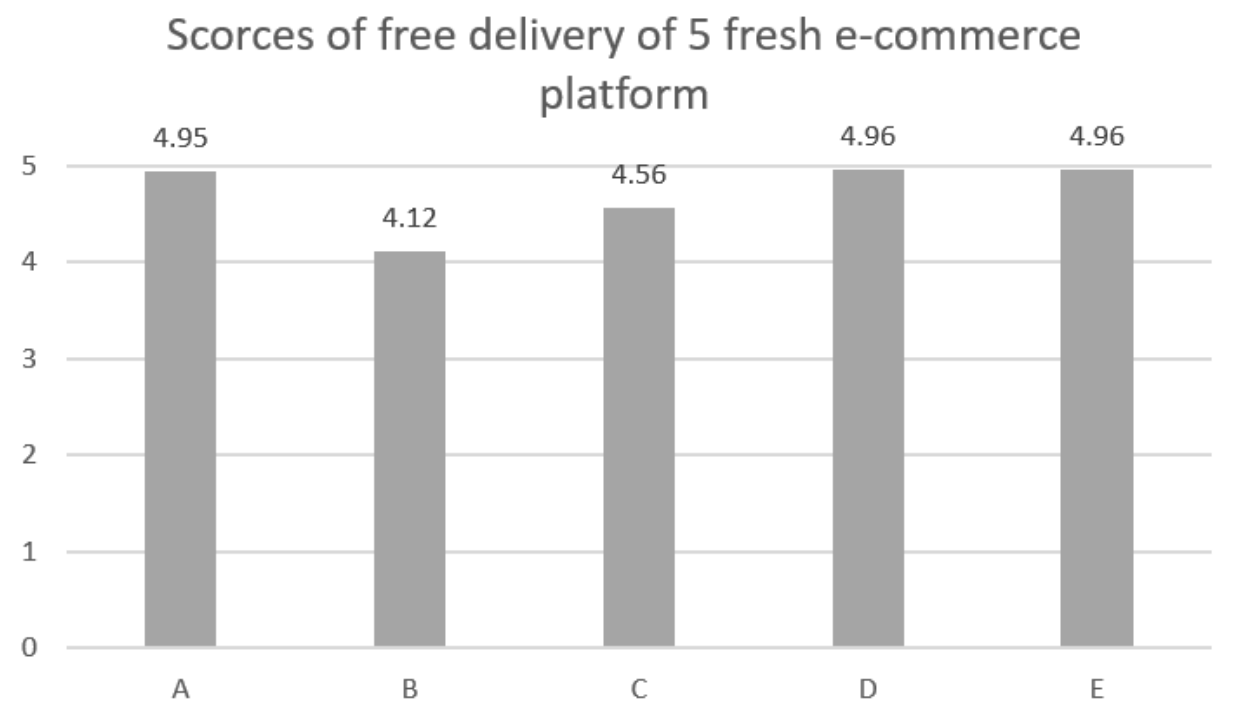

Figure 3. Evaluation of minimum consumption of "free distribution fee" of fresh e-commerce

\subsection{Comparative analysis of memberships}

Several fresh e-commerce companies need to complete the registration information and relevant login interface before they can purchase goods. The membership situation of fresh e-commerce is different from that of traditional retail supermarket. Some members of fresh ecommerce need to purchase in order to enjoy the member discount. However, the fresh e-commerce of traditional offline retail supermarket has no member purchase and no VIP member purchase discount.

For example, A's home page has an obvious entrance to the member zone. Not only do some products have preferential prices and get a free dish every day, but also you can get coupons and enjoy the preferential prices of members. Therefore, for consumers who often use app to purchase goods, it is obviously more cost-effective to purchase member packages, enjoy member discounts and get coupons. B has member price and member activity, can enjoy the preferential price and member discount. As traditional retail brands, $\mathrm{B}$ and $\mathrm{C}$ do not provide online VIP service policy, which is different from $\mathrm{A}, \mathrm{B}$ and $\mathrm{E}$. Two have today's special and other columns.

E has member services, some products have preferential prices, can also get free dishes every day, and provide preferential prices for members.

Both A and B have membership card services. In terms of card opening price, the price of $B$ is higher than that of A. at the same time, the preferential price is less than that of $\mathrm{a}$, and the rights and interests are less. E membership card opening price, member preferential price and preferential service are similar to a. The three fresh e- commerce companies all buy regular members at a certain price. B only provides one-year members. The other two fresh e-commerce companies can choose the consumption cycle by consumers themselves. The longer the purchase cycle, the cheaper the monthly unit price. There is no member upgrade policy for the three appliance companies.

\subsection{Comparative analysis of communities}

The community situation is mainly in the exchange area and post publishing area, and mainly in the new fresh ecommerce. The fresh e-commerce platform of traditional fresh retailers does not have this function. At the same time, through community communication, such as publishing product related posts, you can get points and other e-coins. Through e-coin exchange discount or cash reward, you can encourage consumers to communicate and promote the activity of e-commerce consumers. Therefore, consumers can not only view recipes on the ecommerce platform, but also purchase and communicate, which has become a new platform for consumers to communicate. The above-mentioned a, B and e fresh ecommerce platforms all have these columns for community communication, while the e-commerce platforms of C and D traditional offline supermarkets do not provide such communication space and services.

Comprehensive analysis of the above data shows that the new fresh e-commerce platform has certain advantages over the traditional supermarket e-commerce in terms of delivery quality and delivery time. The delivery time is relatively fast, the free mail price is set lower, and there are more preferential policies and measures to attract consumers to purchase and repeat purchase. It is relatively 
flexible in terms of e-commerce management and operation, which is better than the traditional supermarket More advantages.

\subsection{Comparative analysis of payment preferences}

The preferential payment is mainly provided by the fresh e-commerce platform and the payment platform, including the full reduction discount, brand discount and the full reduction discount activities of fresh e-commerce. The differences among the three are as follows: most of the full discount activities of fresh e-commerce are the preferential behaviours of fresh e-commerce itself, and they can get a certain amount of full discount with the full discount of the whole platform or a certain category or get coupons. Brand discount can get a certain amount of full discount with a certain brand, such as a certain amount of discount when a certain brand product arrives at a certain amount of shopping. They are combined with the payment platform. There are many more subdivision activities, such as the combination of Alipay or WeChat with a bank's credit card or debit card and credit card or debit card discount, which has time limits or quota restrictions.

\subsection{Comparative analysis of interface design of APP}

The friendliness of fresh e-commerce interface of APP is as important as the layout of physical supermarkets. For many consumers, especially some middle-aged and old people who are not familiar with the e-commerce platform, the friendliness of fresh e-commerce interface has a certain relationship with the re purchase rate of the platform.

Taking A platform as an example, the middle position of the home page of the interface clearly shows the classification of categories. It is convenient to turn the page through the left and right sliding scroll bars. At the bottom of the category classification are the attractive functions of inviting friends such as "Limited Time Grab" and "Coupons", which can easily understand the most important shopping information. The function keys at the bottom can simply reach the "Shopping Cart" and "Category Classification" interface. Once you reach the "category classification" interface, you can not only search for products at the top of the screen, but also find categories at the top of the screen or find sub categories on the left side of the screen. Not only that, the category classification at the top of the screen is displayed in the form of icons and words, which has obvious visual impact and is easy to display The effect is clear. At the same time, such a two-dimensional layout is not only convenient for browsing, but also convenient for direct search. For consumers who are not proficient in using the APP for the first time, they can easily master the use method and consume.

The layout of platform B is similar to that of platform A, but you can only enter the specific classification through the classification interface in the middle of the screen, and there is no function key at the bottom of the screen. The fresh food platform pays more attention to community communication and the service of "exchange points after completing tasks". After entering the classification interface through the classification function, the classification interface of B is very similar to that of $A$, but the sorting of categories is not the same. As B is more inclined to sell processing and semi-processing selfoperated products, such processing and semi-processing products are placed in the front position, while platform A is in the front position of vegetable and fruit products. Because of this, platform $\mathrm{B}$ is popular with more office workers, families of three and young people. The food is ready to eat at home or easy to heat. It is rich in variety and fast to get home. It has a very good choice for young people who want to eat at home but do not want to process more food materials, and has heavy taste and do not want to eat too much takeout.

The most prominent position on the home page of $\mathrm{C}$ platform is preferential commodities and some special preferential activities. The form and content tend to the poster form of traditional supermarkets. Although the colour is gorgeous and eye-catching, too much preferential content is slightly obvious, and the content is too much to be easily identified. Commodity classification is at the lower part of the platform, and there is a classification function key at the bottom of the screen, which is consistent with the fresh platform function described above. However, because $\mathrm{C}$ belongs to Online + Offline super e-commerce. There are both "To Home" and "Store" information on the e-commerce platform. Therefore, the e-commerce platform seems to have many and complete functions, but it is a little messy, which is not very convenient to use. At the same time, the entry of thirdparty businesses and "Next Day Arrival" also need consumers to screen before purchasing.

Although platform $\mathrm{D}$ and $\mathrm{C}$ both belong to "Online + Offline" e-commerce, the layout of the home page platform is mainly composed of the dynamic advertisement at the top and the "Special Sale Today" in the middle, while the common category classification can only be found by sliding down the screen, which is the biggest difference from the previous e-commerce platforms. Therefore, when you need to switch to category classification, you need to use the function keys below to switch. However, compared with the $\mathrm{C}$ platform, the preferential information on the home page is clear and clear, which not only successfully attracts the attention of consumers, but also increases the desire to buy special products. After entering the category classification interface, it is also different from the previous e-commerce platforms. The friendliness of the category classification interface is not as good as the previous three platforms. Different from the first three platforms, platform D is in the category classification interface. The major categories listed vertically on the left side of the platform, while the sub categories are on the top of the platform. The identification of the sub categories is not obvious, and the categories and sub categories are single words, so the visual stimulation and attraction are obviously insufficient.

The home page interface and the function keys below of E platform are similar to A and B. when entering the category classification interface, the category 
classification first displayed. The display mode of icon and text is clear at a glance. If a category classification selected, the interface can be automatically folded up. The category classification interface is similar to $\mathrm{A}$ and $\mathrm{B}$, with friendly interface design and convenient operation.
After 100 consumers evaluating on the friendliness of the above five fresh e-commerce interfaces, it can be seen that A, B and E have higher scores, with friendly interface and better operation; $\mathrm{C}$ and $\mathrm{D}$ have lower scores, as shown in Figure 4.

\section{Scores of interface presentation of 5 fresh e- commerce platfomr}

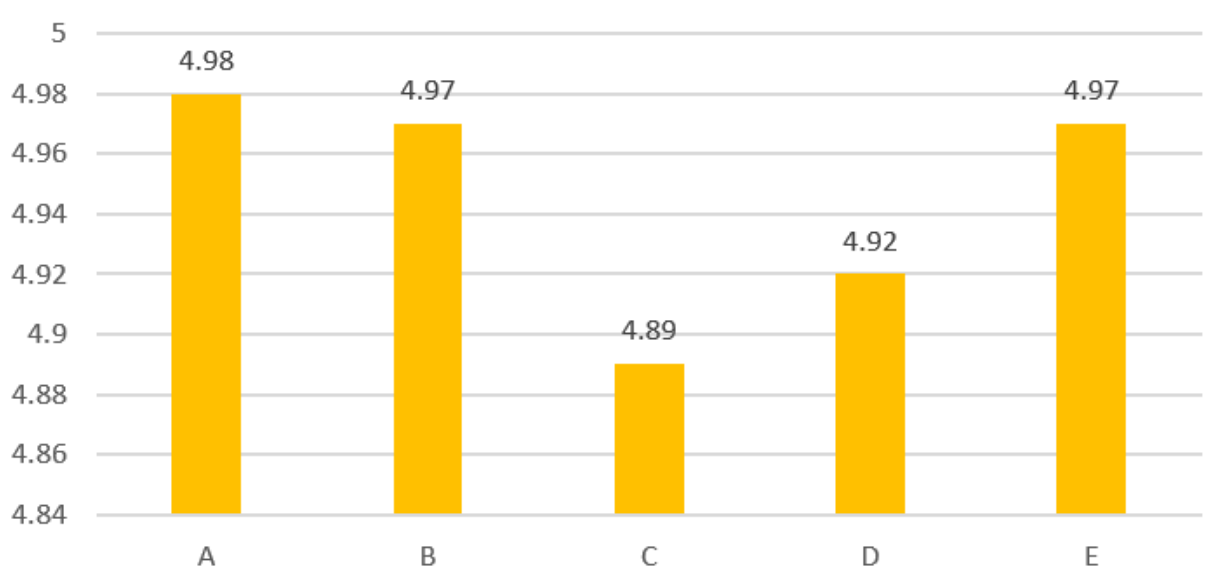

Figure 4. Evaluation of friendly degree of interface presentation of fresh e-commerce

\section{Analysis summary of categories and services of fresh e-commerce}

Based on the above four evaluation items, we rank them in the order of average score: $\mathrm{A}>\mathrm{E}>\mathrm{D}>\mathrm{C}>\mathrm{B}$.

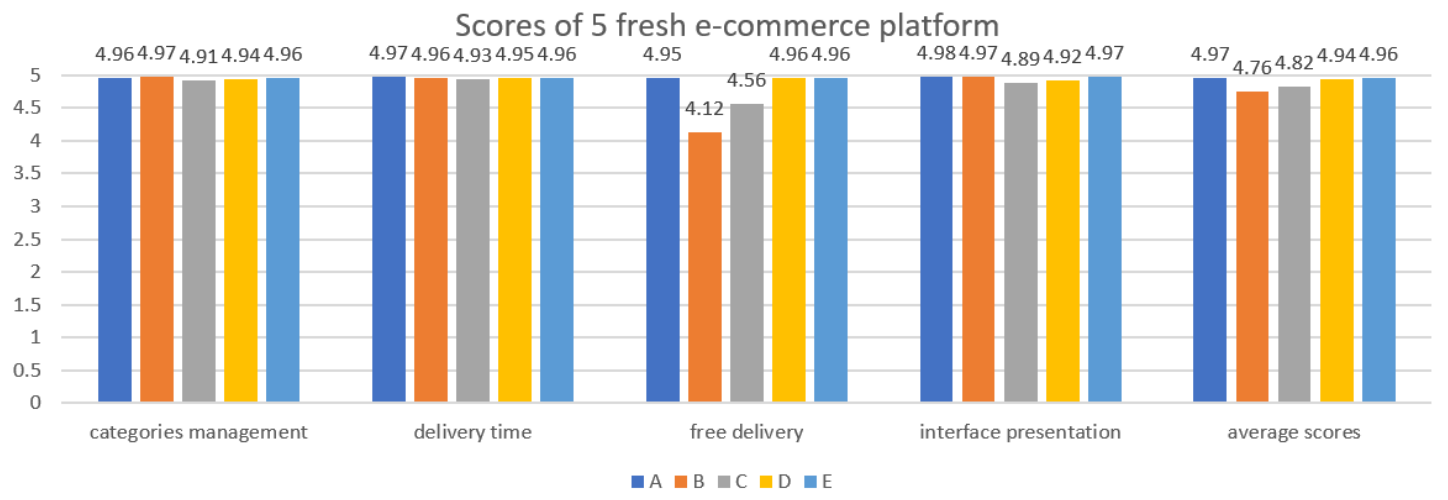

Figure 5. The Scores of 5 fresh e-commerce platform

The traditional retail industry is being impacted by the new fresh e-commerce. More and more young and middleaged people have requirements for consumption demand and consumption habits. They choose fresh e-commerce as the channel of fresh purchase to achieve faster speed, higher quality and more commodity categories. The price is no longer the only factor for consumers. Fresh ecommerce platform with its own characteristics of the operation model is attracting the attention of different consumers. Price is no longer the only factor for consumers, especially young and middle-aged consumers. Punctual service, high-quality products and rich product choices are all factors that consumers consider comprehensively. Therefore, it has become an important competitive weight in the market to provide consumers with higher quality and differentiated services through consumer market segmentation.

\section{References}

1. Ping An Securities. The panorama report of fresh retail industry in 2020 [EB/OL]. http://www.100ec.cn/detail--6551308.html,2020-0407

2. Tao Yao. Discussion on ecological and service quality improvement of fresh e-commerce industry in China [J]. Research on commercial economy, 2020 (16) :9598

3. Yangyang Liu. Big data driven fresh agricultural products supply chain model innovation and operation optimization $[\mathrm{J}]$. Research on commercial economy, 2020 (16): 150-152 
4. Deng Yiping. The Innovation Approach of China's Retail Profit Model under the New Retail Background [J]. Journal of Hubei Open Vocational College, 2020,33(13): 136-138.

5. Li Mengxia, Shui Wenbing. Research on the Influencing Factors of Online Presale Purchase Intention of Fresh Agricultural Products-Base on the Theory of Reasoned Action [J]. Logistics Sci-Tech, 2020,43(08): 7-11.

6. Wang Mengbo. An Analysis of the Factors Influencing Consumer Decision to Purchase Fresh Agricultural Products [J]. Journal of Wuxi Vocational Institute of Commerce, 2019, 19(1): 22-30.

7. Asadi M, Ganjibakhsh M, Aghdam S M, et al. Establishment and Preservation of Lymphoblastoid Cell Lines from Fresh and Frozen Whole Blood and Mononuclear Cells[J]. In Vitro Cellular \& Developmental Biology - Animal, 2020, 56(4): 332340.

8. Mcknight D H, Choudhury V, Kacmar C. Developing and Validating Trust Measures for e-Commerce: An Integrative Typology[J]. Information Systems Research, 2002, 13(3):344-359.

9. Yanyong. Research of Order Allocation of Ecommerce Logistics Service Supply Chain Considering Customer Evaluation[J]. International Journal of Plant Engineering and Management, 2020, 15(1):1-13.

10. Bergstein H, Nesin B. Five considerations for marketers navigating the changing US beverage alcohol e-commerce landscape[J]. Journal of Digital \& Social Media Marketing, 2020, 8(13): 33-45.

11. Rabiah A S, Fahlevi M, Juhandi N, et al. Haruskah EPayment Trust Diterapkan E-Commerce Sebagai Faktor Kepuasan Konsumen? [J]. E-Jurnal Manajemen Universitas Udayana, 2020, 9(7):27242743.

12. Xin Q, Yijie W. Analysis and Prospect of Fresh Agricultural Products E-commerce Development in China[J]. Agricultural Outlook, 2019, 15(10): 136139.

13. Kumar A, Salo J, Li H. Stages of User Engagement on Social Commerce Platforms: Analysis with the Navigational Clickstream Data[J]. International Journal of Electronic Commerce, 2019, 23(2):179211.

14. Wang Jin, Yan Haolong. Research on the Supply Chain Operation Model of Fresh Agricultural Products under the Social Economy [J]. Journal of Anhui Agricultural Sciences, 2021, 49(1): 169-171.

15. Zan Mengying, Chen Guang, Wang Zhengbing. Development of E-commerce of Fresh Agricultural Products in China: Progress, Difficultiesand Strategies [J]. On Economic Problems, 2020(12): 6874 